\title{
O Hospital Santa Izabel (HSI) como hospital de ensino
}

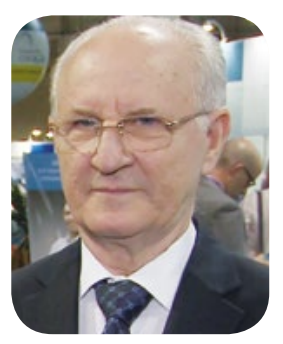

\author{
Gilson Soares Feitosa', Patrícia Alcântara Viana²
}

Os hospitais de ensino no Sistema de Saúde cumprem um papel muito relevante no desempenho de quatro funções principais: formação de recursos humanos, construção do conhecimento por meio da pesquisa científica, desenvolvimento de novas tecnologias e atendimento dos casos de alta complexidade.

Após a criação da Diretoria de Ensino e Pesquisas em 2005, iniciou-se o processo de credenciamento do HSI como Hospital de Ensino junto ao MEC/MS, o que veio a ocorrer em 2006 e como corolário a contratualização com a SMS, como tal, em 2008.

Tais fatos formalizaram uma ação que já se desenvolvia amplamente no HSI, que sempre teve sua vocação direcionada e reconhecida de proporcionar um ambiente propício à assistência e ao ensino.

A abrangência dessa ação de ensino encontra-se amplamente documentada nos números apresentados nas tabelas 1 e 2 abaixo, referentes ao esforço realizado na graduação e na pós-graduação.

Tabela 1. Atividade de Ensino de Graduação no HSI 2017

\begin{tabular}{llll}
\hline \hline \multirow{2}{*}{ Convênio } & \multicolumn{2}{c}{ Ensino na Graduação } & \\
& EBMSP & Disciplinas & $\begin{array}{l}\mathrm{N}^{\circ} \text { de alu- } \\
\text { nos/sem. }\end{array}$ \\
& Medicina & Internato de clínica médica & 100 \\
& Medicina & Semiologia & 50 \\
& Medicina & Ortopedia e traumatologia & 30 \\
& Medicina & Otorrinolaringologia & 30 \\
& Fisioterapia & Prática observacional & 20 \\
& Fisioterapia & Fisioterapia hospitalar & 20 \\
& Psicologia & Psicologia hospitalar & 4 \\
& Biomedicina & Análises clínicas & 2 \\
& & & \\
\hline
\end{tabular}

\begin{tabular}{|c|c|c|c|}
\hline & Enfermagem & Saúde do adulto & 6 \\
\hline $\begin{array}{c}\text { Ruy } \\
\text { Barbosa }\end{array}$ & Psicologia & Psicologia hospitalar & 2 \\
\hline \multirow[t]{2}{*}{ FTC } & Farmácia & Farmácia hospitalar & 20 \\
\hline & Farmácia & Oncologia & 2 \\
\hline \multirow[t]{4}{*}{ UNEB } & Farmácia & Farmácia hospitalar & 6 \\
\hline & Farmácia & Oncologia & 2 \\
\hline & Enfermagem & Estágio curricular & 12 \\
\hline & Administração & Estágio curricular & 20 \\
\hline UCSal & Serviço Social & Estágio hospitalar I, II e III & 3 \\
\hline \multirow[t]{2}{*}{ UFBA } & Serviço Social & Estágio hospitalar & 2 \\
\hline & Odontologia & Odontologia hospitalar & 2 \\
\hline \multirow[t]{7}{*}{ UNIFACS } & Nutrição & Estágio em produção & 30 \\
\hline & Nutrição & Nutrição parenteral & 30 \\
\hline & Biomedicina & Análises clínicas & 2 \\
\hline & Biomedicina & Bioimagem & 12 \\
\hline & Farmácia & Farmácia hospitalar & 40 \\
\hline & Farmácia & Oncologia & 2 \\
\hline & Enfermagem & Estágio hospitalar & 6 \\
\hline $\begin{array}{l}\text { SENAI/ } \\
\text { CIMATEC }\end{array}$ & Engenharia & Engenharia clínica & 2 \\
\hline Total & & & 457 \\
\hline
\end{tabular}

Tabela 2. Atividade de Pós-graduação Senso Lato no HSI 2017

\begin{tabular}{cc}
\hline \hline Residência Médica & Vagas \\
Anestesiologia & 16 \\
Cancerologia clínica & 7 \\
Cardiologia & 12 \\
Cardiologia pediátrica & 1 \\
Cirurgia do aparelho digestório & 3
\end{tabular}




\begin{tabular}{cc} 
Cirurgia geral & 8 \\
Clínica médica & 16 \\
Hemodinâmica & 2 \\
Medicina intensiva & 6 \\
Neurologia & 9 \\
Ortopedia & 16 \\
Otorrinolaringologia & 9 \\
Pneumologia & 2 \\
Reumatologia & 2 \\
Urologia & 6 \\
Terapia intensiva & 10 \\
Oncologia & 18 \\
Nutrição clínica & 10 \\
Total de vagas & 153 \\
\hline
\end{tabular}

Para as aulas teóricas ou teórico-práticas são disponibilizadas 5 salas de treinamento com 163 lugares, 1 auditório com 150 lugares, um anfiteatro com 80 lugares e com recurso de videoconferência.

Em 2016 foram agendadas 3.587 atividades nas salas entre sessões clínicas, reuniões científicas, discussões de casos e treinamentos operacionais e comportamentais.

Sem dúvida, o HSI tem contribuído dessa forma para estender a muitos, na Bahia e alhures, uma oportunidade de atendimento mais qualificado ao cidadão enfermo, cumprindo assim uma das suas mais destacadas missões.

Essa ação benemérita tem merecido ao longo dos anos um inestimável apoio do Estado, do Município e das Instituições Acadêmicas com que nos relacionamos, notadamente a Escola Bahiana de Medicina e Saúde Pública.

Muito do que aqui se realiza se deve diretamente ao espírito dos que constituem o ambiente do HSI, sempre atentos a fazer o melhor possível, com dedicação, esmero e com responsabilidade para com os cidadãos e a Instituição, procurando garantir-lhe a sustentabilidade.

A alta gestão da Santa Casa da Bahia, na figura do Sr. Provedor, tem sido fundamental nesse desenvolvimento.

No último Congresso Brasileiro de Escolas Medicas (COBEM) fomos agraciados com o convite para, no Simpósio da Associação Brasileira de Hospitais Universitários e de Ensino (ABRAHUE), apresentar- mos no contexto "Qualificação do Cenário de Prática Hospitalar: Experiências Exitosas dos HUE. Hospital de Ensino Filantrópico = Hospital Santa Izabel da Santa Casa da Bahia".

Ficamos muito lisonjeados com o reconhecimento e comprometidos a manter o rumo e estimulados ao próximo passo da criação da Pós-graduação Senso Estrito de Mestrado e Doutorado.

Vamos ao desafio!

1- Editor da Revista Científica do HSI

2- Gerente de Ensino e Pesquisa do HSI

Endereço para correspondência: gilson-feitosa@uol.com.br 